\title{
An Assessment of the Efficiency of Dust Regional Modelling to Predict Saharan Dust Transport Episodes
}

\author{
D. K. Papanastasiou, ${ }^{1}$ A. Poupkou, ${ }^{2}$ E. Katragkou, ${ }^{2}$ V. Amiridis, ${ }^{3}$ D. Melas, ${ }^{2}$ N. Mihalopoulos, ${ }^{4}$ \\ S. Basart, ${ }^{5}$ C. Pérez, ${ }^{6}$ and J. M. Baldasano ${ }^{5}$ \\ ${ }^{1}$ Laboratory of Agricultural Engineering and Environment, Institute of Technology and Management of Agricultural Ecosystems, \\ Centre for Research and Technology - Thessaly, Technology Park of Thessaly, 1st Industrial Area of Volos, 38500 Volos, Greece \\ ${ }^{2}$ Laboratory of Atmospheric Physics, Aristotle University of Thessaloniki, Campus Box 149, 54124 Thessaloniki, Greece \\ ${ }^{3}$ Institute for Space Applications \& Remote Sensing, National Observatory of Athens, Metaxa and Vas. Paulou street, \\ 15236 Penteli, Greece \\ ${ }^{4}$ Environmental Chemical Processes Laboratory, Department of Chemistry, University of Crete, P.O.Box 2208, Voutes, \\ 71003 Heraklion, Greece \\ ${ }^{5}$ Earth Sciences Division, Barcelona Supercomputing Center, Nexus II Building, c/ Jordi Girona 29, 08034 Barcelona, Spain \\ ${ }^{6}$ Earth Institute at Columbia University, NASA Goddard Institute for Space Studies and International Research Institute for \\ Climate and Society, 405 Low Library, MC 4335, 535 West 116th Street, NY 10027, USA
}

Correspondence should be addressed to D. K. Papanastasiou,dkpapan@auth.gr

Received 17 May 2010; Accepted 19 July 2010

Academic Editor: Harry D. Kambezidis

Copyright ( 2010 D. K. Papanastasiou et al. This is an open access article distributed under the Creative Commons Attribution License, which permits unrestricted use, distribution, and reproduction in any medium, provided the original work is properly cited.

Aerosol levels at Mediterranean Basin are significantly affected by desert dust that is eroded in North Africa and is transported northwards. This study aims to assess the performance of the Dust REgional Atmospheric Model (BSC-DREAM8b) in the prediction of dust outbreaks near the surface in Eastern Mediterranean. For this purpose, model PM10 predictions covering a 7-year period and PM10 observations at five surface monitoring sites in Greece are used. A quantitative criterion is set to select the significant dust outbreaks defined as those when the predicted PM10 surface concentration exceeds $12 \mu \mathrm{g} / \mathrm{m}^{3}$. The analysis reveals that significant dust transport is usually observed for 1-3 consecutive days. Dust outbreak seasons are spring and summer, while some events are also forecasted in autumn. The seasonal variability of dust transport events is different at Finokalia, where the majority of events are observed in spring and winter. Dust contributes by 19-25\% to the near surface observed PM10 levels, which can be increased to more than $50 \mu \mathrm{g} / \mathrm{m}^{3}$ during dust outbreaks, inducing violations of the air quality standards. Dust regional modeling can be regarded as a useful tool for air quality managers when assessing compliance with air quality limit values.

\section{Introduction}

A large portion of atmospheric Particulate Matter (PM) is derived from arid regions of the Earth (North Africa, Arabian Peninsula, central Asia, Australia, etc.) and is distributed all over the globe. Saharan desert is responsible for up to half of the global mineral dust emissions, thus it is considered as the most important dust source worldwide [1]. Once in the atmosphere, dust aerosols induce serious environmental and health effects [2]. They influence the Earth's radiation balance as they interact with solar and thermal radiation, causing large uncertainties in assessing climate forcing by atmospheric aerosols [3], they impact on photololysis rates and ozone chemistry by modifying UV radiation [4], and they contribute to the increase of PM levels over populated areas. Therefore, the estimation of the dust load over an area as well as its contribution to aerosols surface concentration is crucial for the implementation of air quality and generally environmental management policies.

The North African desert dust cycle depends on the synoptic circulations, which control the frequency and extent of transport and on the washout by precipitation which influences the residences time of dust particles in the atmosphere. The bulk of the dust is transported 


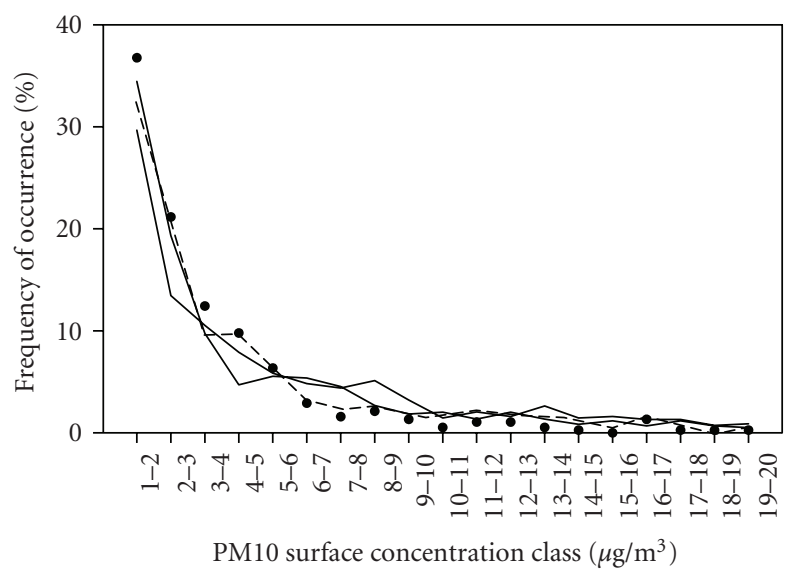

Figure 1: Frequency distribution of modelled PM10 surface concentrations. Finokalia: solid line; Thrakomakedones: bold solid line; Volos: dashed line; Panorama: dots.

westward into the Atlantic Ocean and an unnegligible part is transported northward across the Mediterranean basin to southern and even central Europe [5-7]. The dust cycle presents a marked seasonal variation and the more intense outbreaks are observed in summer $[5,8]$. The Mediterranean dust is found to be multilayered within a wide range of altitudes, penetrating rather higher in the troposphere [9]. During strong perturbations, dust can reach up to $10 \mathrm{~km}$ in altitude and may last there for several days [10]. A detailed description of the synoptics that control the dust transport over the Mediterranean is given by Barkan et al. [7].

Regional modelling is considered as a useful tool to simulate and predict the dust cycle in the atmosphere. The Dust REgional Atmospheric Model (DREAM) [11] has reached a level of delivering reliable operational dust forecasts capable to predict all the major dust events over Mediterranean. It solves the Euler-type partial differential nonlinear equation for dust mass continuity. During model integration, calculation of the surface dust injection fluxes is made over the model grid points declared as deserts. The concentration equation simulates all major processes of the atmospheric dust cycle, namely, production, diffusion, advection, and removal. DREAM is already exploited in several studies. Viana et al. [12] applied it in combination with the MM5 meteorological model to interpret the levels and composition of particulate matter at the greater Barcelona area. Pérez et al. [13] report that the simulated dust horizontal and vertical structure shows very good qualitative agreement when compared to satellite images and lidar observations over Barcelona. Balis et al. [14] also found that there is a good agreement on the thickness and location of the dust layer between the model simulation and the lidar measurements recorded in Thessaloniki. However, Gerasopoulos et al. [15] state that the model shows a tendency to underpredict the atmospheric optical depth values and the surface PM10 concentrations in Athens urban area, where local anthropogenic emissions are significant. As the model undergoes significant revisions in order to improve the forecasting ability, there is a need for continuous validation by comparison of model results with observations. The model could be validated using PM surface concentrations monitored in rural and/or urban areas, as well as remote sensing observations.

The aim of this study is to examine the capability of the updated version of DREAM at the Barcelona Supercomputer Center (BSC-DREAM8b, [13]) to predict the occurrence of Saharan dust transport episodes in the Eastern Mediterranean. Data recorded at five Greek sites (two urban, two suburban and one rural) are analyzed. The study is focused on the days when a dust outbreak is clearly predicted by the model. Therefore, a critical concentration value is firstly defined so as to select the dust transport events. The analysis covers the period 2001-2007.

\section{Materials and Methods}

2.1. Near Surface PM10 Data. PM10 data recorded automatically at five monitoring sites in Greece are exploited in this study (Table 1). Finokalia monitoring station is a member of the EMEP measurement network, while the rest four stations are members of the national network of air pollution monitoring that is developed by the Hellenic Ministry for the Environment, Physical Planning \& Public Works (current title since 2009: Hellenic Ministry for the Environment, Energy \& Climate Change). The stations have been selected in order to represent all geographic parts of Greece, for example, south (Finokalia, Heraklion), central (Thrakomakedones, Volos), and north (Panorama) parts of the country.

2.2. Model Outputs. The updated version of DREAM model, BSC-DREAM8b $[13,16]$, has been delivering operational dust forecasts over the North Africa-Mediterranean-Middle East and over Asia regions in the last years in the BSC (currently at http://www.bsc.es/projects/earthscience/DREAM/). The partial differential nonlinear equation for dust mass continuity is resolved in the Eulerian mode. BSC-DREAM8b is forced by the NCEP/Eta meteorological driver [17-21]. In this latest version of the model, the aerosol description is improved from 4 to 8 bins and dust-radiation interactions are included. As shown by Haustein et al. [22] for the SAMUM-I field campaign, BSC-DREAM8b (with increased number of dust size bins) transports the dust more efficient since the small particle size range $(<10 \mu \mathrm{m}$ effective radius) is better described. Furthermore, as shown in the annual evaluation of the model against AERONET data [23] for southern Europe, also good agreement is found with correct temporal representation of AOD peaks. BSC-DREAM8b distinguishes well between events and no-events, although the amplitude of the dusty events is generally underestimated. Finally, BSCDREAM8b shows better results during the wet episodes due to the modified wet deposition scheme that it includes.

For the present study, simulation is initialized with 24hourly (at 00UTC) updated NCEP (National Centers for Environmental Prediction) $0.5^{\circ} \times 0.5^{\circ}$ analysis data and the initial state of dust concentration in the model is defined by the 24-hour forecast from the previous-day model run because there are not yet satisfactory three-dimensional dust 
TABLE 1: PM10 monitoring sites ${ }^{1}$.

\begin{tabular}{lccccc}
\hline Monitoring site & Latitude $(\mathrm{N})$ & Longitude $(\mathrm{E})$ & Altitude $(\mathrm{m})$ & Type & Data availability $(\%)$ \\
\hline Heraklion & $35.30^{\circ}$ & $25.13^{\circ}$ & 10 & Urban & 71 \\
Finokalia & $35.33^{\circ}$ & $25.67^{\circ}$ & 150 & Background & 70 \\
Thrakomakedones & $38.14^{\circ}$ & $23.76^{\circ}$ & 550 & Suburban & 82 \\
Volos & $39.37^{\circ}$ & $22.94^{\circ}$ & 31 & Urban & 82 \\
Panorama & $40.59^{\circ}$ & $23.03^{\circ}$ & 330 & Suburban & 81 \\
\hline
\end{tabular}

${ }^{1}$ Data from Heraklion and Finokalia stations are available for the periods 2001-2005 and 2004-2007, respectively, while the rest refer to the whole study period (2001-2007).

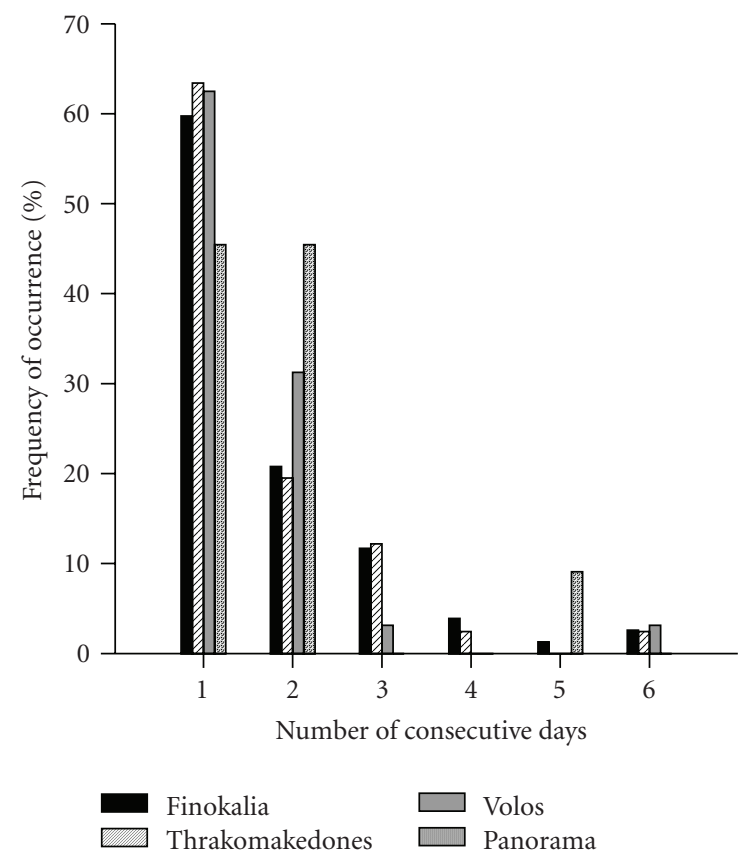

(a)

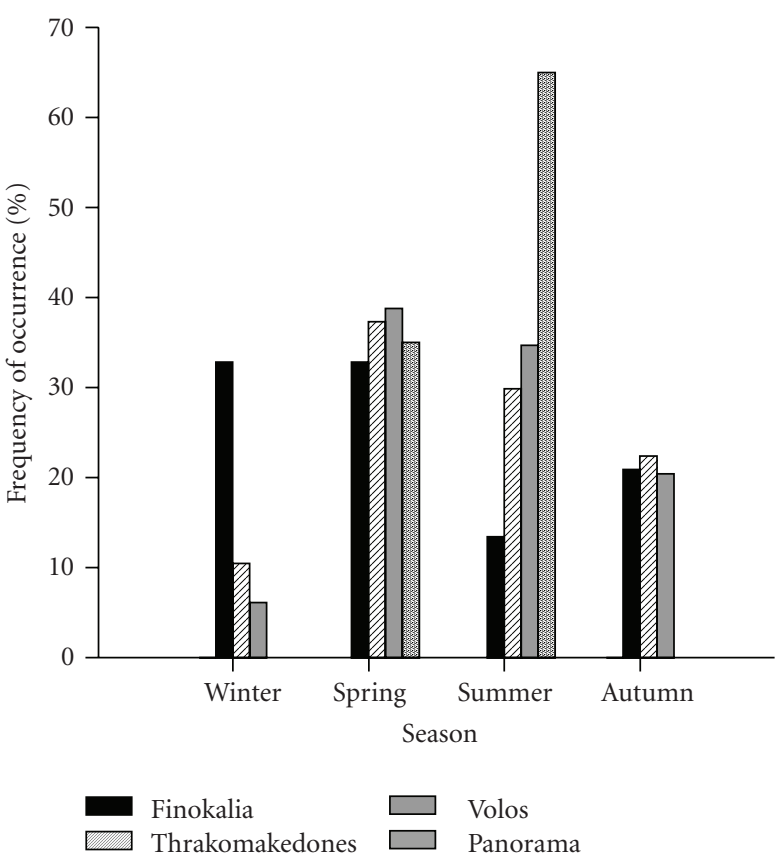

(b)

FIGURE 2: (a) Duration and (b) seasonality of the most significant dust outbreaks according to BSC-DREAM8b.

concentration observations to be assimilated. Only in the "cold start" of the model, concentration is set to zero. The cold start of the model was initiated on 21 December 2003. The resolution is set to $1 / 3^{\circ}(\sim 50 \mathrm{~km})$ in the horizontal and to 24 layers extending up to approximately $15 \mathrm{~km}$ in the vertical.

BSC-DREAM8b's simulations regarding the contribution of transported dust to surface PM10 concentration at Finokalia, Thrakomakedones, Volos, and Panorama are exploited in this study. As Finokalia station is situated $70 \mathrm{~km}$ northeast of Heraklion, and although Heraklion is included in an adjacent model's grid point, it is assumed that the contribution of transported dust to surface PM10 concentration at Heraklion is the same as at Finokalia.

\section{Results and Discussion}

3.1. Selection of Dust Transport Events. In this study, the capability of the BSC-DREAM8b to simulate the desert dust transported in the Eastern Mediterranea especially during dust outbreaks is examined. Therefore, model outputs have to be filtered so as to select the most important dust transport events that significantly influence surface PM10 levels. It was decided to define one threshold for all monitoring stations, based on the modelled PM10 surface concentrations. For this purpose, modelled PM10 surface concentrations are classified and the critical part of their distribution is presented in Figure 1. Studying the tail of the distribution, it is revealed that the frequency of occurrence becomes rather constant when the concentration exceeds the value of $10 \mu \mathrm{g} / \mathrm{m}^{3}$. Additionally, modelled values are well converged when concentration becomes $12 \mu \mathrm{g} / \mathrm{m}^{3}$. So, it could be assumed that significant dust transport and deposition occurs when BSC-DREAM8b simulates surface concentration over $12 \mu \mathrm{g} / \mathrm{m}^{3}$. Consequently, it is decided to set this value as the selection threshold. This limit value corresponds to the 5th, 3rd, 2nd, and 1st upper percentile of the predicted PM10 surface concentrations at Finokalia, Thrakomakedones, Volos, and Panorama, respectively. These 


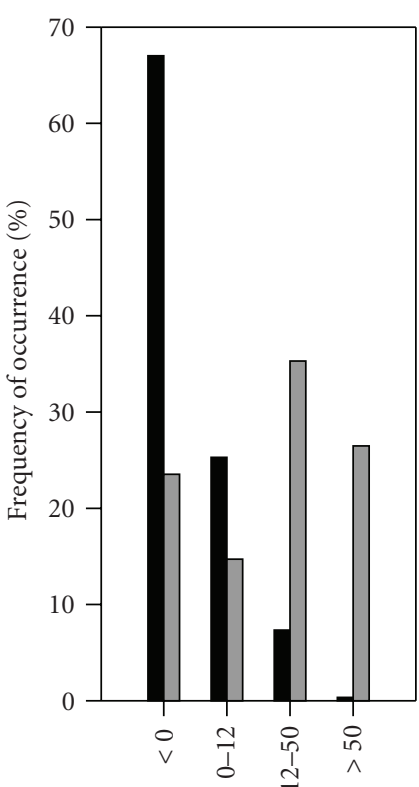

Short-term component of PM10 concentration $\left(\mu \mathrm{g} / \mathrm{m}^{3}\right)$

(a)

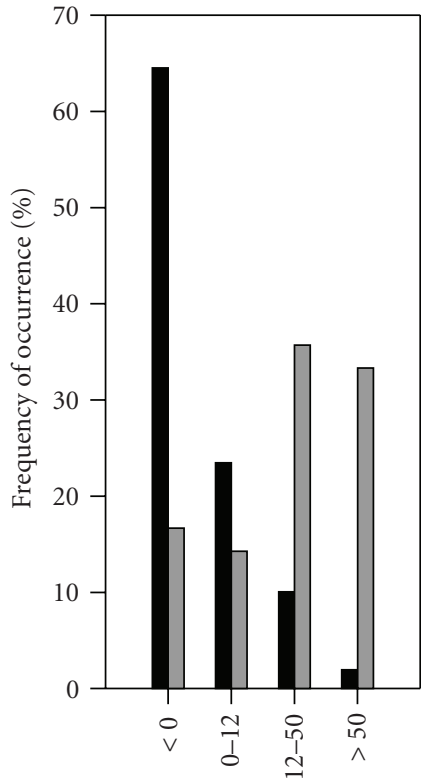

Short-term component of PM10 concentration $\left(\mu \mathrm{g} / \mathrm{m}^{3}\right)$

(b)

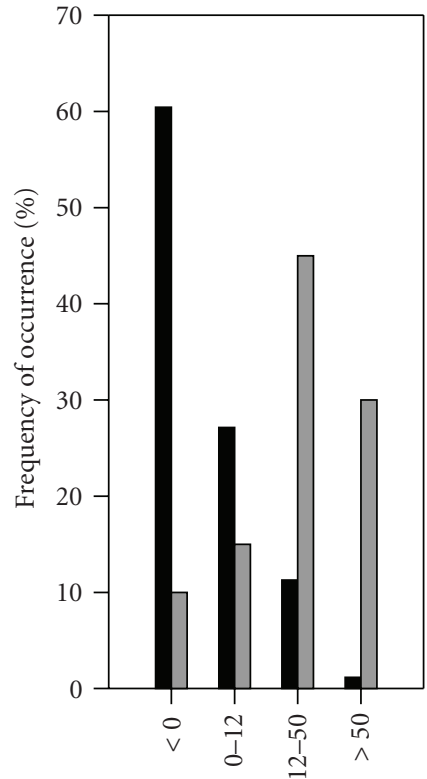

Short-term component of PM10 concentration $\left(\mu \mathrm{g} / \mathrm{m}^{3}\right)$

(c)

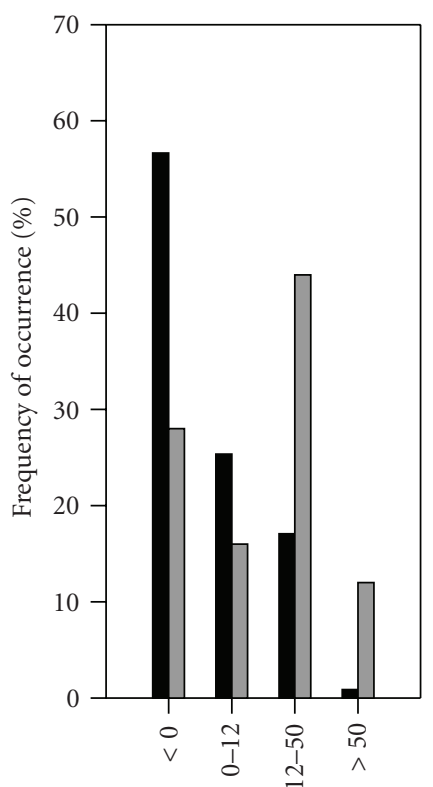

Short-term component of PM10 concentration $\left(\mu \mathrm{g} / \mathrm{m}^{3}\right)$

(d)

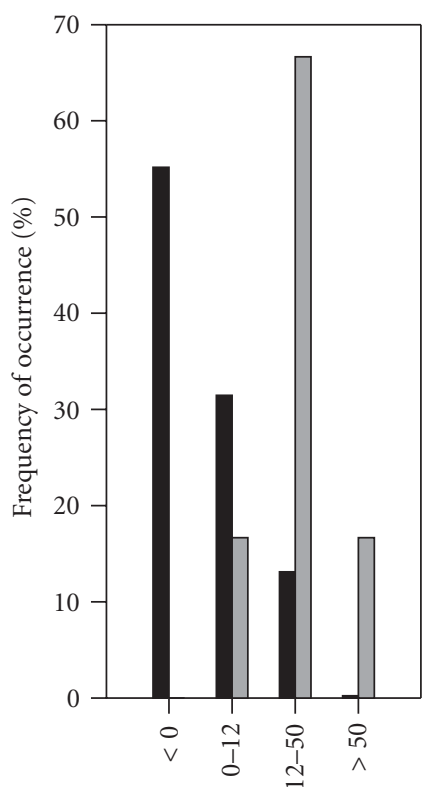

Short-term component of PM10 concentration $\left(\mu \mathrm{g} / \mathrm{m}^{3}\right)$

(e)

FIGURE 3: Frequency distribution of the short-term component of the observed PM10 concentrations at (a) Finokalia, (b) Heraklion, (c) Thrakomakedones, (d) Volos, and (e) Panorama; Grey bars correspond to the days when a dust outbreak is identified, while black bars correspond to the rest of the days.

percentiles verify that only significant dust outbreaks are selected.

3.2. Application of the Selection Criterion. The criterion that is defined above is applied to the time series predicted by BSC-DREAM8b. Quantitative information about the selected events is provided in Table 2. Table 2 reveals that the defined threshold is very restrictive for sites located mainly to the northern part of Greece (e.g., Panorama). This fact indicates that the definition of an overall European or national threshold is not very useful for planning control strategies on a regional level. In this case, it would be better if 
TABLE 2: Statistics for the selected dust outbreaks during the examined 7-year period.

\begin{tabular}{lcccc}
\hline & Finokalia & Thrakomakedones & Volos & Panorama \\
\hline $\begin{array}{l}\text { Number of days when predicted PM10 } \\
\text { surface concentration exceeds the threshold } \\
\text { value }\left(12 \mu \mathrm{g} / \mathrm{m}^{3}\right)\end{array}$ & 134 & 67 & 49 & 20 \\
\hline Number of events identified & 78 & 41 & 32 & 11 \\
\hline
\end{tabular}

different thresholds are regionally defined, taking also into account local emissions and meteorological conditions, in order to assess the impact of transported dust on surface PM levels. It is also worth mentioning that the results referring to Panorama, that are reported in this study, should be treated with caution, as just a few dust outbreaks are identified.

The duration of the selected events is presented in Figure 2(a). The duration of the dust events is similar at Finokalia and Thrakomakedones, while episodes of shorter duration are identified at Volos and Panorama. As far as the longer events identified, two 6-day and one 5-day events are detected at Finokalia. One of the two 6-day events that are predicted at Finokalia coincides with the 6-day event that is detected at Thrakomakedones and Volos and the 5-day event that is detected at Panorama. This dust outbreak could be regarded as the most significant during the examined period not only due to its long duration but also due to its large spatial extent. This event coincided with the heat wave episode that influenced the Eastern Mediterranean during the last days of June 2007. Therefore, it contributed not only to the aggravation of air quality in Greece but also to the deterioration of discomfort conditions that were prevailing due to the extremely high air temperatures [24].

The seasonal distribution of the selected events is presented in Figure 2(b), which shows that the dust transport exhibits an annual cycle. Most of the outbreaks are observed during spring and summer, some outbreaks are observed during autumn and a very limited number during winter. This result is in accordance to the conclusions drawn by Moulin et al. [5] who analyzed satellite observations and found that the dust transport from North Africa to the Mediterranean Basin is favoured from March to August, while during autumn and winter dust transport is less pronounced. Papayannis et al. [8] analyzed lidar data in Athens and Thessaloniki obtained during an almost 3-year period and reported that the period when the more important Saharan dust transport occurred over the Eastern Mediterranean is summer followed by autumn. The present study suggests that autumn could also be considered as a period with important dust outbreaks over the Eastern Mediterranean, as $\sim 20 \%$ of the selected events are predicted during autumn months. Dust transport over Greece is favoured during the warmer months of the year, when the prevailing meteorological situation is characterized by western-south-western synoptic flows, a condition that favours the transport of dust from North Africa [25]. However, the seasonal pattern of the southernmost station of Finokalia exhibits some differences and is discussed in detail by Kalivitis et al. [26]. Koulouri et al. [27] report that according to measurements contacted at
Finokalia station during the period July 2004-July 2006, the seasonal variability of the masses of coarse particles, which are defined as those that have aerodynamic diameter between 1.3 and $10 \mu \mathrm{m}$, presents a prominent peak in spring (April) and a secondary one in February, both due to dust transport from North Africa. This is in agreement with the results of BSC-DREAM8b for the seasonality of serious dust events at Finokalia as shown in Figure 2(b).

3.3. Evaluation of BSC-DREAM8b. BSC-DREAM8b's outputs are compared to surface PM10 observations. The efficiency of the model to predict dust transport episodes is discussed and the contribution of transported desert dust to the determination of surface PM10 concentrations at the areas studied is presented. Predicting PM concentrations in time and space is important for air quality and health concerns, weather prediction, and climate studies. As dust transport events influence surface levels for relatively short time periods, it is preferred to compare the model's results to the short-term component of measured PM10 concentration. Short-term variations are attributed to weather processes. They could be separated from the original time series by using the Kolmogorov-Zurbenko $(K Z m, p)$ filter [28]. The KZ filter is a low-pass filter produced through $p$ repeated iterations of a moving average calculated over an $\mathrm{m}$ time window that can provide time series that does not include short-term periodicities. Then, by subtracting the filtered time series from the original one, the time series of the short-term component of measured PM10 concentration is generated. According to Rao et al. [29], the application of a $\mathrm{KZ}_{15,5}$ filter is the best choice to remove the short-term part of the time series. This technique has widely been applied in ozone studies $[30,31]$ in order to separate a time series into different temporal components, while its application has also been extended in PM studies [32].

In this study, the $\mathrm{KZ}_{15,5}$ filter is applied to the time series of the observed daily average PM10 concentration. Days are separated in two groups. One group includes the days when a dust outbreak is identified by the application of the selection criterion that is presented above, while the other group includes the rest of the days. The short-term component is classified and the frequency of occurrence of each class for every group is presented in Figure 3. Figure 3 reveals that during the majority of the days selected as dust episodes according to the results of BSC-DREAM8b, the values of the short-term component are positive, indicating an increase in PM10 levels that could be partially attributed to the transport of desert dust. However, for several days that are included in the first group, the values of the short-term component 
TABLE 3: Contribution of transported dust to near surface PM10 levels ${ }^{1}$.

\begin{tabular}{lcccccccccccc}
\hline Site & \multicolumn{3}{c}{ Case a } & \multicolumn{3}{c}{ Case b } & \multicolumn{3}{c}{ Case c } & \multicolumn{2}{c}{ Case d } \\
\hline & $\mathrm{S}$ & $\mathrm{R}^{2}$ & $\mathrm{~N}$ & $\mathrm{~S}$ & $\mathrm{R}^{2}$ & $\mathrm{~N}$ & $\mathrm{~S}$ & $\mathrm{R}^{2}$ & $\mathrm{~N}$ & $\mathrm{~S}$ & $\mathrm{R}^{2}$ & $\mathrm{~N}$ \\
Finokalia & 1.48 & 0.44 & 33 & 3.69 & 0.64 & 45 & 2.61 & 0.74 & 17 & 5.32 & 0.82 & 18 \\
Thrakomakedones & 2.06 & 0.49 & 40 & 3.96 & 0.68 & 59 & 2.58 & 0.86 & 29 & 5.04 & 0.80 & 30 \\
Volos & 1.19 & 0.42 & 25 & 3.55 & 0.83 & 36 & 1.92 & 0.71 & 13 & 4.08 & 0.83 & 13 \\
Panorama & 1.80 & 0.85 & 12 & 3.77 & 0.95 & 12 & 1.99 & 0.92 & 10 & 3.94 & 0.97 & 10 \\
\hline
\end{tabular}

${ }^{1} \mathrm{~S}$ : Slope of the regression line; $\mathrm{R}^{2}$ : Squared Correlation Coefficient regarding the regression procedure; N: Number of Days included in the regression analysis.

are lower than the selection threshold $\left(12 \mu \mathrm{g} / \mathrm{m}^{3}\right)$ or are even negative. Negative values indicate that the simulation of BSC-DREAM8b concerning the occurrence of a dust episode might be false. However, negative values of the short-term component can also be caused by local effects (e.g., related to the weekly variation of PM10 levels), especially at urban or suburban sites. Positive values lower than $12 \mu \mathrm{g} / \mathrm{m}^{3}$ indicate that the BSC-DREAM8b model might be successful in the prediction of the occurrence of a dust outbreak; however, it fails to estimate the magnitude of the dust being transported. More specifically, negative values are calculated for the 24 , $17,10,28$, and $0 \%$ of the days at Finokalia, Heraklion, Thrakomakedones, Volos, and Panorama, respectively, while positive values lower than $12 \mu \mathrm{g} / \mathrm{m}^{3}$ are calculated for the 15 , $14,15,16$, and $17 \%$ of the days, respectively. The short-term component of the daily average value of PM10 concentration raises more than $12 \mu \mathrm{g} / \mathrm{m}^{3}$ during the $61,69,75,56$, and $83 \%$ of the days at Finokalia, Heraklion, Thrakomakedones, Volos, and Panorama, respectively. Violations of the Air Quality Standard (AQS) are observed during all of these days at Heraklion (29 days), Volos (14 days), and Panorama (10 days) and during the 86 and $93 \%$ of these days at Finokalia (18 days) and Thrakomakedones (28 days), respectively, as the daily average value of PM10 concentration exceeds $50 \mu \mathrm{g} / \mathrm{m}^{3}$. The limit value is established by the European Union's Directive 1999/30 and is kept by the Directive 2008/50, which recently replaced the former Directive. This fact indicates that when BSC-DREAM8b achieves to predict a significant dust outbreak, an AQS exceedance will most probably be observed. Additionally, the number of exceedances at Heraklion and Thrakomakedones is close to the allowed number of exceedances, which is set equal to 35 according to the above-mentioned Directives. However, it should be pointed out that Directive 2008/50 states that where natural contributions to pollutants in ambient air can be determined with sufficient certainty, and where exceedances are due in whole or in part to these natural contributions, these may be subtracted when assessing compliance with air quality limit values. The results of the present study and dust regional modelling in general can be useful in the development of air pollution control strategies.

It should be noted though that the increase in PM10 levels, observed during the days when dust events take place according to BSC-DREAM8b, could be attributed not only to the transported dust but also to the local meteorological conditions that are prevailing during dust outbreaks. It is well known that specific meteorological conditions could favour the accumulation of dust as well as the accumulation of pollutants that are locally emitted due to anthropogenic activities. Moreover, anthropogenic as well as natural emissions of PM10 undergo a significant temporal variation that could mask the influence of the transported Saharan dust.

The analysis of the data that refer to the selected events is extended in order to quantify the contribution of the transported dust to the observed near surface PM10 levels. For this reason, model predictions are compared to PM10 observations, as well as to their short-term component. Four cases are examined. Case (a): model predictions are compared to the short-term component of the PM10 observations. Case (b): model predictions are compared to the PM10 observations. Case (c): model predictions are compared to the short-term component of PM10 observations, only when the short-term component of PM10 concentrations is higher than the value forecasted by the model. Case (d): model predictions are compared to the PM10 observations, only when the short-term component of PM10 concentrations is higher than the value forecasted by the model. The results of the cases (a) and (b) include uncertainties as model's possible mispredictions are not excluded from the analysis. The results of cases (c) and (d) are more indicative as the introduction of the criterion regarding the short-term component cuts off the possible mispredicted events and allows the inclusion in the analysis of only those days when dust transport could have contributed to the increase of the observed PM10 levels.

A regression line is calculated for every site for each of the cases examined, considering the model's prediction as the independent variable and the PM10 concentration or its short-term component as the dependent one. Additionally, intercept is forced to zero. The results of all regressions are presented in Table 3. Table 3 shows that model's predictions are better correlated to the PM10 observations than to their short-term component, with just one exception (Thrakomakedones, cases (c) and (d)). This fact could be attributed to the variability of the anthropogenic emissions that have diurnal and weekly cycles and moreover to meteorological phenomena that also present variations of one or more days, such as the sea breeze circulation and synoptic winds. The influence of the above factors and phenomena is probably masked by the application of the $\mathrm{KZ}_{15,5}$ filter, since their variability is much shorter than the 15-day window of the filter applied. The slope values when model predictions are regressed to PM10 observations are higher than when 
regressed to their short-term component indicating the contribution of additional sources other than desert to the determination of surface PM10 levels in the areas studied.

According to the analysis of case (c), dust contribution accounts for the 38,39,52, and $50 \%$ of the increase in PM10 concentrations at Finokalia, Thrakomakedones, Volos, and Panorama, respectively, while according to the results of case (d), the 19,20,25, and $25 \%$ of the measured PM10 concentrations is attributed to dust transport. The percentage differences support the conclusion drawn above regarding the drawback of the application of the KZ filter.

As Finokalia is a background site, it was expected that dust contribution to surface PM10 levels would be relatively higher. This fact indicates that BSC-DREAM8b probably underestimates the dust transported at Finokalia station during the dust outbreaks and that the background PM10 levels at this site could be influenced not only by the transported desert dust but also by particles emitted by other natural sources. Gerasopoulos et al. [33] state that ions and particulate carbonaceous matter could also contribute to PM10 mass, although they report that PM10 levels at Crete are mainly influenced by desert dust during dust outbreaks. According to the previous analysis, the desert dust contribution accounts for the $39 \%$ of the increase in PM10 concentrations at Thrakomakedones. Thrakomakedones station is located to the north of the Athens Basin and PM10 levels there are affected also by anthropogenic emissions. This fact is closely linked to the sea breeze circulation that frequently develops in Athens Basin during the warm period of the year $[34,35]$. Most of the cases that are involved in the regression analysis correspond to spring and summer days. Sea breeze is associated to winds blowing from southeast directions that advect pollutants that are released at the heavily industrialized south-western part of the urban agglomeration, as well as at the city centre, to the north part of the Athens Basin where Thrakomakedones are located. The estimated dust contribution to the PM10 levels at Volos and Panorama could be regarded as reasonable. Volos is a medium-sized coastal city where anthropogenic emissions are high during the cold period of the year [36]. Local emissions are less intense during the warm period. The vast majority of the dust transport events that are included in the regression analysis correspond to spring and summer days. Therefore, it can be supported that although Volos is an urban site, PM10 levels could be significantly influenced by dust transport during the selected outbreaks. As far as Panorama is concerned, it is considered as a suburb that is not significantly affected by anthropogenic emissions [25]. The results presented and the conclusions drawn above should be further verified by future studies including even longer timeseries than the 7-year timeseries used in the present analysis.

\section{Conclusions}

The objective of this study is to assess the efficiency of BSCDREAM8b model to predict Saharan dust transport episodes in the Eastern Mediterranean. For this reason, model outputs that cover the period 2001-2007 are compared to PM10 data recorded by five automatic monitoring stations in Greece. A quantitative criterion is established in order to select the most important dust outbreaks. When modelled surface concentration becomes higher than $12 \mu \mathrm{g} / \mathrm{m}^{3}$, significant dust transport and deposition is assumed to occur.

The duration of the selected events is longer at the monitoring sites located to south Greece (namely, Finokalia and Thrakomakedones). A significant dust outbreak that lasted more than 5 days is detected at all sites in June 2007. This event coincided with the heat wave episode that influenced the Eastern Mediterranean, contributing to the aggravation of air quality and discomfort conditions.

Dust transport is more favoured during summer and spring at Thrakomakedones, Volos, and Panorama and during winter and spring at Finokalia. Additionally, 20\% of the selected dust outbreaks at Finokalia, Thrakomakedones, and Volos are observed during autumn, therefore autumn could also be considered as a season when important dust transport events occur over the Eastern Mediterranean.

In order to evaluate BSC-DREAM8b outputs, the modelled values are compared to the daily average values of surface PM10 concentration, as well as to their shortterm component. Short-term variations are attributed to weather processes and do not include seasonal or long term variations. The short-term component is separated by applying a $\mathrm{KZ}_{15,5}$ filter to the original time series and then by subtracting the filtered time series from the original one. The values of the short-term component are positive (indicating an increase in PM10 levels) and higher than $12 \mu \mathrm{g} / \mathrm{m}^{3}$ (indicating contribution of transported dust to PM10 levels reliably) during the $61,69,75,56$, and $83 \%$ of the days identified as dust outbreaks at Finokalia, Heraklion, Thrakomakedones, Volos, and Panorama, respectively. During the rest of these days, the model fails either to simulate the occurrence of a dust episode or to estimate its magnitude. However, it is found that modelled values correlate better with PM10 observations than with their short-term component, as the application of the $\mathrm{KZ}_{15,5}$ filter probably masks the influence of some factors and meteorological phenomena that have periodicities much shorter than the 15-day window of the applied filter (e.g., anthropogenic emissions with diurnal and weekly cycles, sea breeze circulation). The comparison between the model's predictions and the shortterm component of PM10 observations reveals that dust contribution accounts for the $38,39,52$, and $50 \%$ of the increase in PM10 concentrations at Finokalia, Thrakomakedones, Volos, and Panorama, respectively, while the comparison between the model's predictions and PM10 observations shows that the 19, 20, 25, and 25\% of the measured PM10 concentrations at Finokalia, Thrakomakedones, Volos, and Panorama, respectively, is attributed to dust transport.

\section{Acknowledgment}

The work has been financed by the MED-APICE project in co financed by the European Regional Development Fund in the framework of the MED Programme. 


\section{References}

[1] C. S. Zender, R. L. Miller, and I. Tegen, "Quantifying mineral dust mass budgets: terminology, constraints, and current estimates," Eos, vol. 85, no. 48, pp. 509-512, 2004.

[2] WHO, WHO Air Quality Guidelines Global Update 2005, World Health Organization, Bonn, Germany, 2005.

[3] IPCC, W. G. I.: Climate change 2007: the physical science basis, Summary for Policy Makers, Contribution of Working Group I to the 4th Assessment Report of the Intergovernmental Panel on Climate Change, 2007.

[4] H. Liao, J. H. Seinfeld, P. J. Adams, and L. J. Mickley, "Global radiative forcing of coupled tropospheric ozone and aerosols in a unified general circulation model," Journal of Geophysical Research D, vol. 109, no. 16, 33 pages, 2004.

[5] C. Moulin, C. E. Lambert, U. Dayan et al., "Satellite climatology of African dust transport in the Mediterranean atmosphere," Journal of Geophysical Research D, vol. 103, no. 11, pp. 13137-13144, 1998.

[6] J. Barkan, H. Kutiel, P. Alpert, and P. Kishcha, "Synoptics of dust intrusion days from the African continent into the Atlantic Ocean," Journal of Geophysical Research D, vol. 109, no. 8, article no. D08201, 9 pages, 2004.

[7] J. Barkan, P. Alpert, H. Kutiel, and P. Kishcha, "Synoptics of dust transportation days from Africa toward Italy and central Europe," Journal of Geophysical Research D, vol. 110, no. 7, article no. D07208, pp. 1-14, 2005.

[8] A. Papayannis, D. Balis, V. Amiridis et al., "Measurements of Saharan dust aerosols over the eastern Mediterranean using elastic backscatter-Raman lidar, spectrophotometric and satellite observations in the frame of the EARLINET project," Atmospheric Chemistry and Physics, vol. 5, no. 8, pp. 20652079, 2005.

[9] A. Di Sarra, T. Di Iorio, M. Cacciani, G. Fiocco, and D. Fuà, "Saharan dust profiles measured by lidar at Lampedusa," Journal of Geophysical Research D, vol. 106, no. 10, pp. 1033510347, 2001.

[10] G. P. Gobbi, F. Barnaba, R. Giorgi, and A. Santacasa, "Altitude-resolved properties of a Saharan dust event over the Mediterranean," Atmospheric Environment, vol. 34, no. 29-30, pp. 5119-5127, 2000.

[11] S. Nickovic, G. Kallos, A. Papadopoulos, and O. Kakaliagou, "A model for prediction of desert dust cycle in the atmosphere," Journal of Geophysical Research D, vol. 106, no. 16, pp. 1811318129, 2001.

[12] M. Viana, C. Pérez, X. Querol, A. Alastuey, S. Nickovic, and J. M. Baldasano, "Spatial and temporal variability of PM levels and composition in a complex summer atmospheric scenario in Barcelona (NE Spain)," Atmospheric Environment, vol. 39, no. 29, pp. 5343-5361, 2005.

[13] C. Pérez, S. Nickovic, J. M. Baldasano, M. Sicard, F. Rocadenbosch, and V. E. Cachorro, "A long Saharan dust event over the western Mediterranean: Lidar, Sun photometer observations, and regional dust modeling," Journal of Geophysical Research D, vol. 111, no. 15, article no. D15214, 2006.

[14] D. Balis, V. Amiridis, S. Kazadzis et al., "Optical characteristics of desert dust over the east Mediterranean during summer: a case study," Annales Geophysicae, vol. 24, no. 3, pp. 807-821, 2006.

[15] E. Gerasopoulos, P. Kokkalis, V. Amiridis et al., "Dust specific extinction cross-sections over the Eastern Mediterranean using the BSC-DREAM model and sun photometer data: the case of urban environments," Annales Geophysicae, vol. 27, no. 7, pp. 2903-2912, 2009.
[16] C. Pérez, S. Nickovic, G. Pejanovic, J. M. Baldasano, and E. Özsoy, "Interactive dust-radiation modeling: a step to improve weather forecasts," Journal of Geophysical Research D, vol. 111, no. 16, article no. D16206, 2006.

[17] Z. I. Janjic, "Pressure gradient force and advection scheme used for forecasting with steep and small scale topography," Contributions to Atmospheric Physics, vol. 50, pp. 186-199, 1977.

[18] Z. I. Janjic, "Forward-backward scheme modified to prevent twogrid-interval noise and its application in sigma coordinate models," Contributions to Atmospheric Physics, vol. 52, pp. 6984, 1979.

[19] Z. I. Janjic, "Nonlinear advection schemes and energy cascade on semi-staggered grids," Monthly Weather Review, vol. 112, no. 6, pp. 1234-1245, 1984.

[20] Z. I. Janjic, "The step-mountain coordinate: physical package," Monthly Weather Review, vol. 118, no. 7, pp. 1429-1443, 1990.

[21] Z. I. Janjic, "The step-mountain eta coordinate model: further developments of the convection, viscous sublayer, and turbulence closure schemes," Monthly Weather Review, vol. 122, no. 5, pp. 927-945, 1994.

[22] K. Haustein, C. Pérez, J. M. Baldasano et al., "Regional dust model performance during SAMUM 2006," Geophysical Research Letters, vol. 36, no. 3, article no. L03812, 2009.

[23] S. Basart, C. Pérez, E. Cuevas, and J. M. Baldasano, "Evaluation of a regional mineral dust model over Northern Africa, Southern Europe and Middle East with AERONET data," in Proceedings of the EGU General Assembly, vol. 11 of Geophysical Research Abstracts, Vienna, Austria, 2009, EGU2009-10799.

[24] D. K. Papanastasiou, D. Melas, T. Bartzanas, and C. Kittas, "Temperature, comfort and pollution levels during heat waves and the role of sea breeze," International Journal of Biometeorology, vol. 54, no. 3, pp. 307-317, 2010.

[25] E. Katragkou, S. Kazadzis, V. Amiridis, V. Papaioannou, S. Karathanasis, and D. Melas, "PM10 regional transport pathways in Thessaloniki, Greece," Atmospheric Environment, vol. 43, no. 5, pp. 1079-1085, 2009.

[26] N. Kalivitis, E. Gerasopoulos, M. Vrekoussis et al., "Dust transport over the eastern mediterranean derived from total ozone mapping spectrometer, aerosol robotic network, and surface measurements," Journal of Geophysical Research D, vol. 112, no. 3, article no. D03202, 2007.

[27] E. Koulouri, S. Saarikoski, C. Theodosi et al., "Chemical composition and sources of fine and coarse aerosol particles in the Eastern Mediterranean," Atmospheric Environment, vol. 42, no. 26, pp. 6542-6550, 2008.

[28] I. G. Zurbenko, The Spectral Analysis of Time Series, North Holland, New York, NY, USA, 1986.

[29] S. T. Rao, I. G. Zurbenko, R. Neagu, P. S. Porter, J. Y. Ku, and R. F. Henry, "Space and time scales in ambient ozone data," Bulletin of the American Meteorological Society, vol. 78, no. 10, pp. 2153-2166, 1997.

[30] M. L. Milanchus, S. T. Rao, and I. G. Zurbenko, "Evaluating the effectiveness of ozone management efforts in the presence of meteorological variability," Journal of the Air and Waste Management Association, vol. 48, pp. 201-215, 1998.

[31] J. Yang and D. R. Miller, "Trends and variability of groundlevel O3 in Connecticut over the period 1981-1997," Journal of the Air and Waste Management Association, vol. 52, no. 12, pp. 1354-1361, 2002.

[32] E. K. Wise and A. C. Comrie, "Extending the KolmogorovZurbenko filter: application to ozone, particulate matter, and meteorological trends," Journal of the Air and Waste Management Association, vol. 55, no. 8, pp. 1208-1216, 2005. 
[33] E. Gerasopoulos, G. Kouvarakis, P. Babasakalis, M. Vrekoussis, J.-P. Putaud, and N. Mihalopoulos, "Origin and variability of particulate matter (PM10) mass concentrations over the Eastern Mediterranean," Atmospheric Environment, vol. 40, no. 25, pp. 4679-4690, 2006.

[34] D. Melas, I. Ziomas, O. Klemm, and C. S. Zerefos, "Anatomy of the sea-breeze circulation in Athens area under weak largescale ambient winds," Atmospheric Environment, vol. 32, no. 12, pp. 2223-2237, 1998.

[35] D. Melas, I. Ziomas, O. Klemm, and C. S. Zerefos, "Flow dynamics in Athens area under moderate large-scale winds," Atmospheric Environment, vol. 32, no. 12, pp. 2209-2222, 1998.

[36] D. K. Papanastasiou and D. Melas, "Application of PM10's statistical distribution to air quality management-a case study in central Greece," Water, Air, and Soil Pollution, vol. 207, no. 1-4, pp. 115-122, 2010. 

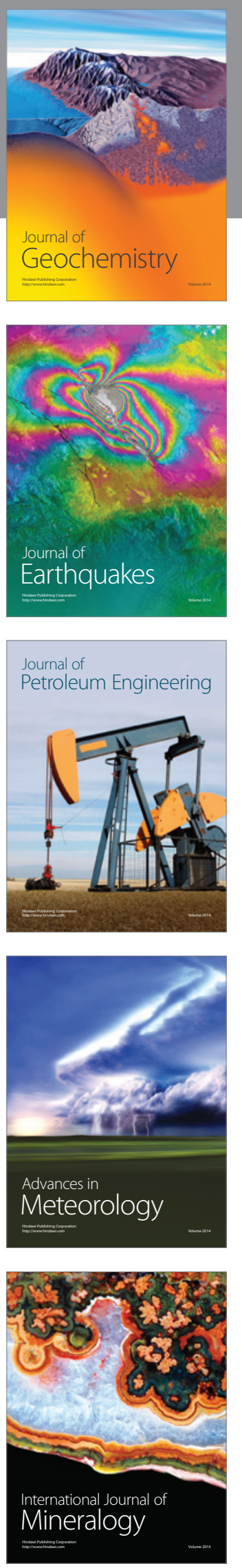
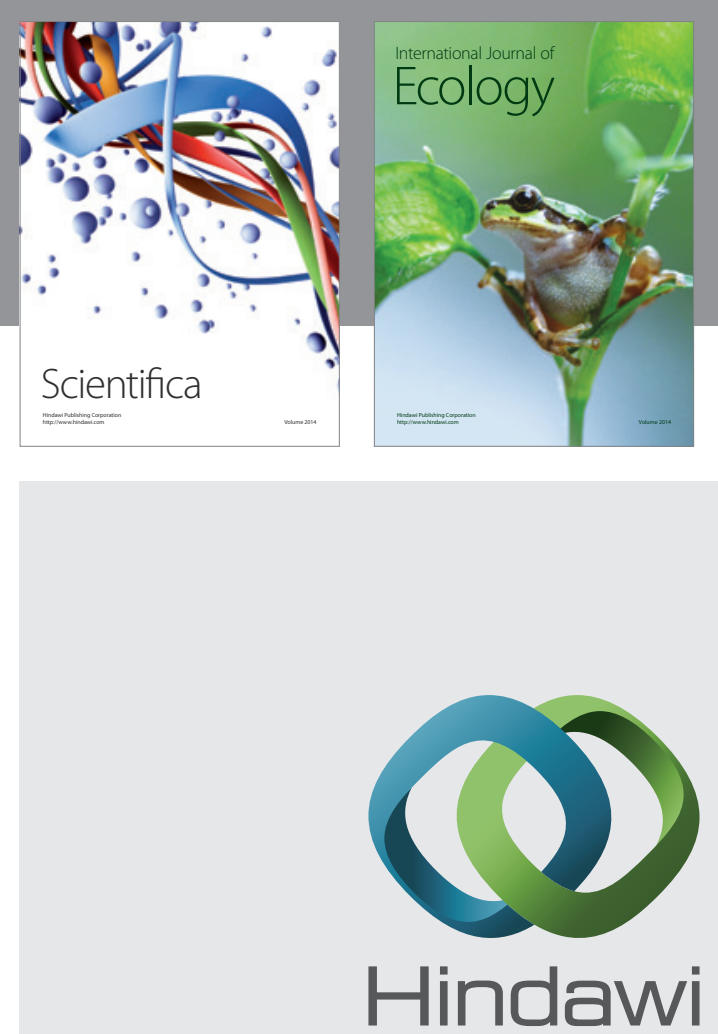

Submit your manuscripts at http://www.hindawi.com
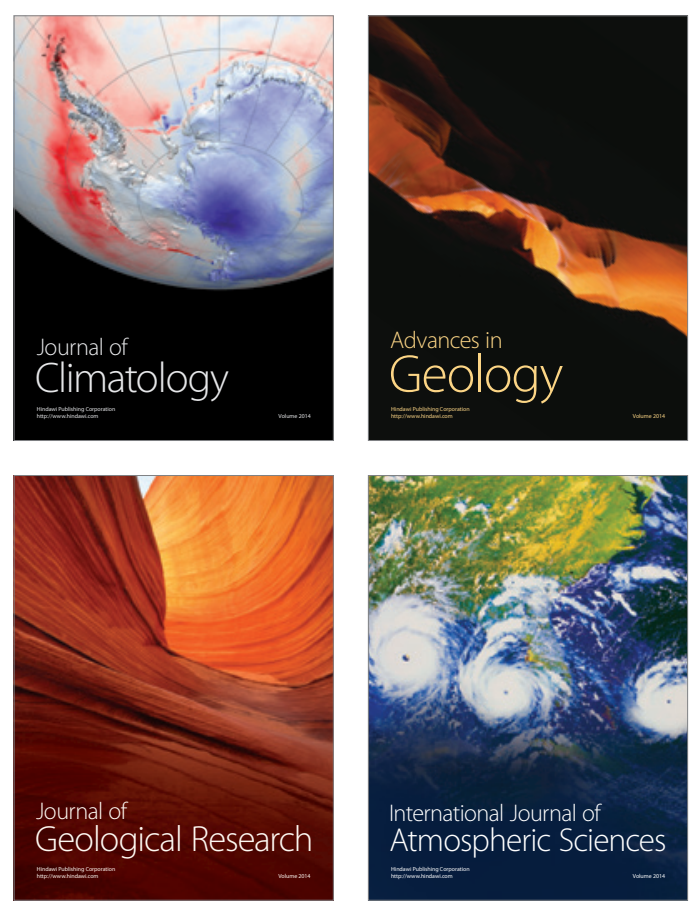
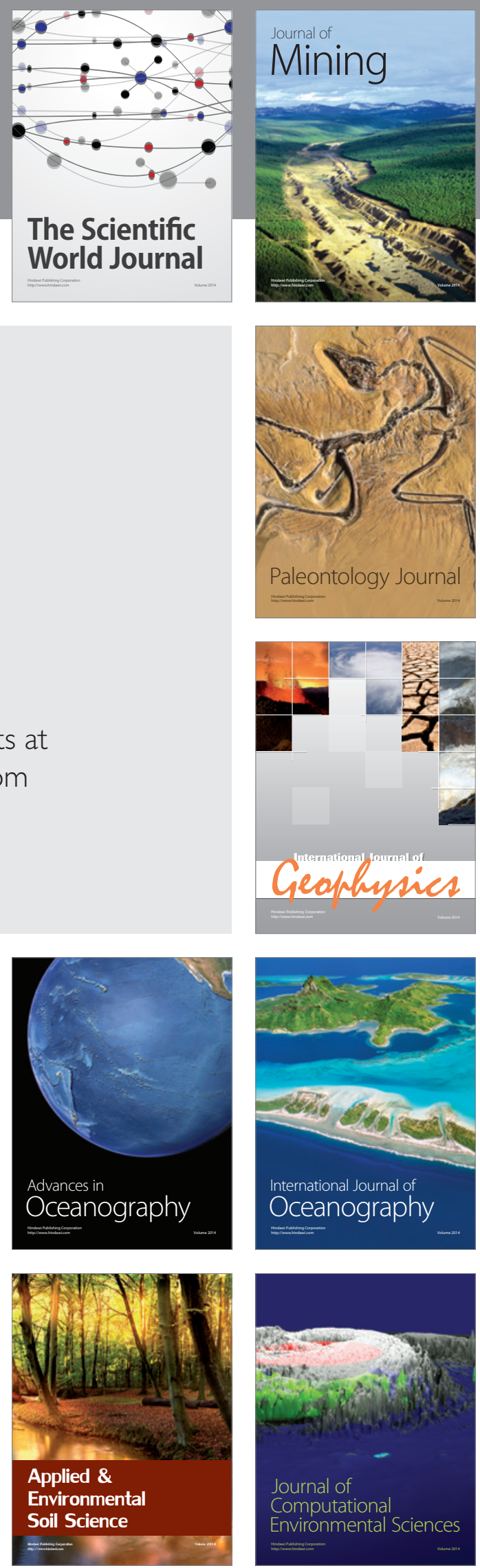